\title{
MODIFICATION OF THE POROUS STRUCTURE ALONG THE PREPARATION OF ACTIVATED CARBON MONOLITHS WITH $\mathrm{H}_{3} \mathrm{PO}_{4}$ AND $\mathrm{ZnCl}_{2}$
}

\author{
Y. Nagakawa, M. Molina-Sabio*, F. Rodríguez-Reinoso \\ Departamento de Química Inorgánica. Universidad de Alcante. \\ Apartado 99. E-03080 Alicante.Spain
}

\begin{abstract}
Two series of activated carbon monoliths (discs) have been prepared by chemical activation of olive stones with phosphoric acid or zinc chloride, without the use of any binder. A conforming step was introduced between impregnation with the chemical and heat treatment. Two equivalent series of granular activated carbons were also prepared in order to analyse the effect of conforming pressure on the porosity of the final activated carbon. The evolution of microporosity and the micropore size distribution has been followed by gas adsorption $\left(\mathrm{N}_{2}\right.$ at $-196^{\circ} \mathrm{C}$ and $\mathrm{CO}_{2}$ at $\left.0^{\circ} \mathrm{C}\right)$ and immersion calorimetry into three liquids with different molecular dimensions (dichloromethane, benzene and 2,2-dimethylbutane).

The experimental results indicate that activation by both chemicals produce a large development of microporosity but the differences between the granular and monolithic forms are more noticeable when using phosphoric acid. Thus, there is mainly a reduction in the interparticle space and macroporosity during the formation of the discs prepared using zinc chloride whereas there is an additional reduction in the volume and dimension of the meso- and microporosity when using phosphoric acid. The different behaviour of the two chemicals has been related to their effect on the precursor along the impregnation step.
\end{abstract}

Keywords: Activated carbon; activation; calorimetry; microporosity, adsorption.

\section{Introduction}

It is well known that activation with phosphoric acid and zinc chloride develops the microporosity when using cellulosic and lignocellulosic precursors in the manufacture of activated carbon [1-3]. Chemical activation is traditionally carried out in two stages: in the first one the precursor is impregnated with a solution of the chemical and in the second the heat treatment influences the carbonisation process, generating the porosity, which becomes accessible when the chemical is removed by washing [4,5]. Consequently, the modification of the chemical/precursor ratio permits the adjustment of the porosity in the final activated carbon.

\footnotetext{
* Corresponding author. Tel.: +34-96-590-9758; fax: +34-96-590-3454. E-mail adress: m.molina@,ua.es (M. Molina-Sabio)
} 
Although the main objective of impregnation is the homogeneous mixture of the chemical and the precursor, previous works have shown that impregnation also brings about the transformation of the precursor [6-8] and, additionally makes the impregnated material extrudable [9]. This phenomenon has permitted the preparation of binderless activated carbon monoliths by just introducing the impregnated mass into a cylindrical mould and applying heat and pressure [10,11]. The impregnated particles can be consolidated because they liberate a tar which will fill the interparticle space. This tar, which acts as a binder, is carbonised along the heat treatment and provides mechanical rigidity to the monoliths. Since the particles are compacted by pressure the monolithic activated carbon will have a lower interparticle space than the equivalent granular carbon, thus exhibiting a larger adsorption capacity on a volumetric basis. On the other hand, since the plastic properties of the precursor are incremented by the action of the chemical, it would also be possible to narrow the dimension of the pores during the conforming step.

The main objective of this work is to study the effect of the pressure conforming step on the resulting porous structure of the final carbon when using impregnated olive stones as precursor. To reach this objective two series of monolithic activated carbons have been prepared using different concentrations of phosphoric acid and zinc chloride and the results compared with two equivalent series of granular activated carbons.

\section{Experimental}

The precursor, olive stones sieved to 0.1-0.5 mm particle size, was impregnated with a solution of zinc chloride ( $1 \mathrm{~g}$ of precursor for $2 \mathrm{ml}$ of solution) at $85^{\circ} \mathrm{C}$ for $7 \mathrm{~h}$; at the end of this time the temperature was increased until complete dryness. The impregnated 
precursor was conformed under pressure at $150^{\circ} \mathrm{C}$ and $130 \mathrm{MPa}$ using a cylindrical mould with an internal diameter of $2 \mathrm{~cm}$. The disc was later heat treated under a flow of nitrogen $(80 \mathrm{ml} / \mathrm{min})$ in a furnace (heating rate of $1^{\circ} \mathrm{C} / \mathrm{min}$ ) at $500^{\circ} \mathrm{C}$ for two hours. Finally all the $\mathrm{ZnCl}_{2}$ was extracted from the discs by washing, first with a solution of hydrochloric acid and then with distilled water.

Several concentrations of zinc chloride $(14-69 \mathrm{wt} \%)$ were used to prepare the series of discs designated as ZD, with six carbons differentiated by the degree of impregnation $\mathrm{X}_{\mathrm{Zn}}$, which ranges from 0.15 to $1.20 \mathrm{~g}$ of zinc per gram of precursor. For instance, carbon ZD-0.15 is a disc prepared by impregnation with a solution of $14 \mathrm{wt} \%$ of zinc chloride, the evaporation of which leaves $0.15 \mathrm{~g}$ of zinc per gram of olive stone.

A similar series of activated carbon discs has been prepared by activation with solutions of phosphoric acid, series PD. The degree of impregnation covered was $\mathrm{X}_{\mathrm{P}}=0.21-0.90 \mathrm{~g}$ of phosphorous/g of precursor, using solutions with concentrations ranging between 29 and $86 \mathrm{wt} \%$ phosphoric acid. The preparation process was similar to the one described for zinc chloride, although milder experimental conditions were selected because phosphoric acid is a Brönsted acid and strong dehydrating agent. Thus, the impregnation period was $2 \mathrm{~h}$, the pressure conforming was at $100^{\circ} \mathrm{C}$ and the heat treatment was at $450^{\circ} \mathrm{C}$. Washing was carried out only with hot distilled water and the removal was not as effective as for zinc chloride; however, only around $2 \mathrm{wt} \%$ of phosphorous is present in the washed discs.

Two series of granular activated carbons have been prepared as reference, series ZG and PG, using the same experimental conditions except pressure conforming and the particle size (now 1.7-2.0 mm). 
The adsorption isotherms for $\mathrm{N}_{2}\left(-196^{\circ} \mathrm{C}\right)$ and $\mathrm{CO}_{2}\left(0^{\circ} \mathrm{C}\right)$ have determined in a volumetric adsorption system (Omnisorb 610). The volume of narrow micropores, $\mathrm{V}_{\mathrm{CO} 2}$ has been obtained by application of the Dubinin-Raduskevich equation to the $\mathrm{CO}_{2}$ adsorption isotherm [12]. Application of the $\alpha_{\mathrm{S}}$ method to the $\mathrm{N}_{2}$ adsorption data, using the non-porous reference isotherm published in [13], led to the total volume of micropores, $\mathrm{V}_{\mathrm{N} 2}$. The volume of mesopores, $\mathrm{V}_{\mathrm{me}}$, has been deduced by substracting $\mathrm{V}_{\mathrm{N} 2}$ from the volume of nitrogen adsorbed at a relative pressure of 0.99 .

The real density measured with helium has been determined by picnometry in a Accupyc 1330, from Micromeritics. Bulk density has been deduced from the dimensions and weight of the carbon monoliths and be weighing a known volume of gently tapped carbon granules (ASTM standard D2854-89 [14]). Both values of density and the volume adsorbed at $\mathrm{P} / \mathrm{P}_{0}=0.99\left(\mathrm{~V}_{0.99}\right)$ were used to determine the join volume of macropores and interparticle space.

The micropore size distribution of the carbons has been obtained directly by immersion calorimetry using a Tian-Calvet calorimeter (C80D, Setaram). The enthalpy of immersion of each carbon into liquids of different molecular dimension was measured at $30^{\circ} \mathrm{C}$. The enthalpy of immersion for a non-porous reference carbon (V3G, $62 \mathrm{~m}^{2} / \mathrm{g}$ ) was used to calculate the surface area of the carbons accessible to the selected liquids [15]. The micropore size distribution has been determined by plotting the surface area as a function of the minimum kinetic dimension of the liquid: dichloromethane, $0.33 \mathrm{~nm}$; benzene, $0.37 \mathrm{~nm}$; 2,2-dimethylbutane, $0.56 \mathrm{~nm}[16,17]$.

\section{Results}


Table 1 presents the values for the helium and bulk density for some activated carbons. Helium density increases with the degree of activation in all series (it does not reach the value for graphite, $2.23 \mathrm{~g} / \mathrm{cm}^{3}$ because carbonisation was at low temperature and, consequently, uncompleted), whereas the bulk density decreases. This means that the resulting carbon is both richer in carbon and more porous. There are small differences in helium density for granular and conformed carbon series, but the differences among bulk density values are large. Consequently, the main effect of the pressure conforming step is to reduce the volume of interparticle space and porosity. This reduction in volume (voids and porosity in Table 1) is similar when impregnating with both chemicals, thus indicating that the impregnated material is compacted in a similar way for both reactants. However, the volume of micro-and mesoporosity $\left(\mathrm{V}_{0.99}\right.$ in Table 1$)$ is similar in series ZD and ZG for a given degree of impregnation, but this is not the case for series PD and PG. Consequently, the differences between series ZD and ZG are mainly due to the reduction in macroporosity and interparticle space (last column of Table 1) after the pressure conforming step. In the case of series PD and PG the volume of micro- and mesopores is also affected.

Figure 1 includes the $\mathrm{N}_{2}$ adsorption isotherms for the carbons given in Table 1, selected because they have the lowest and highest development of porosity for each series (this means that the isotherms for the rest of carbons of each series are within these isotherms). The evolution of the shape of the isotherm for any series is as follows: the adsorption capacity increases with increasing activation and this is paralleled by a widening of the microporosity. For instance, the isotherm for carbon PG-0.21 is type I whereas that for PG-0.60 is characteristic of a carbon with a heterogeneous microporosity and a high proportion of mesoporosity. The adsorption isotherms for 
granular and monolithic carbons prepared using the same chemical and the same degree of activation show interesting differences. Each carbon from series ZD has a larger adsorption capacity than the equivalent granular carbon $\mathrm{ZG}$, although the differences are small and are a function of the concentration of $\mathrm{ZnCl}_{2}$ along impregnation. At low concentration (ZD-0.15 and ZG-0.15) the isotherms are parallel and the difference is in the uptake at low relative pressure, narrow microporosity; at higher concentration (ZD1.20 and ZG-1.20) the isotherms are common at very low relative pressure and parallel at relative pressure above $\mathrm{P} / \mathrm{P}_{0}=0.4$, this meaning that the differences are in the large size micropores.

On the contrary, the adsorption capacity for carbons of series PD is lower than for PG. When the concentration of acid is low (PD-0.21 and PG-0.21) the more significant changes are in both the amount adsorbed and the knee of the isotherm, whereas at high concentration (PD-0.60 and PG-0.60) the more marked differences are in the slope of the linear portion of the isotherm at high relative pressures. These differences reflect that the effect of conforming on the porosity is more important in the case of phosphoric acid activation.

The adsorption isotherms for $\mathrm{N}_{2}$ and $\mathrm{CO}_{2}$ have been used to determine the total volume of micropores $\mathrm{V}_{\mathrm{N} 2}$, the volume of narrow micropores $\mathrm{V}_{\mathrm{CO} 2}$ and the volume of mesopores $\mathrm{V}_{\mathrm{me}}$; the values have been plotted in Figure 2 as a function of the degree of activation $\left(\mathrm{X}_{\mathrm{Zn}}\right.$ and $\left.\mathrm{X}_{\mathrm{P}}\right)$.

It is important to note the large development of porosity produced by the chemical activation of the precursor, the increase in the volume of micropores being larger at the beginning of the process, whereas the development of mesopores occurs at higher degrees of activation. Consequently, the concentration of the activating chemical 
promotes the widening of porosity and it can then be used to modify the pore size distribution of the final carbon. It seems that the development of porosity reaches a limit for zinc chloride as from $\mathrm{X}_{\mathrm{Zn}}=0.60 \mathrm{~g} / \mathrm{g}$, whereas there is a loss of porosity at high concentrations of phosphoric acid, the volume of micropores decreasing in series PD and PG and the volume of mesopores in series PD.

The widening of micropores with the degree of activation is also deduced from the comparison of the values for total volume of micropores $\mathrm{V}_{\mathrm{N} 2}$ and the volume of narrow micropores $\mathrm{V}_{\mathrm{CO} 2}$ [12]. In three of the four series ( $\mathrm{ZD}, \mathrm{ZG}$ and $\left.\mathrm{PG}\right) \mathrm{V}_{\mathrm{CO} 2}$ keeps almost constant while $\mathrm{V}_{\mathrm{N} 2}$ increases in general terms. Only in series $\mathrm{PD} \mathrm{V}_{\mathrm{CO} 2}$ increases up to values of $X_{P}$ around $0.4-0.6 \mathrm{~g} / \mathrm{g}$, decreasing thereafter. This means that in carbons with low degree of activation of this series the narrow microporosity predominates.

The differences among the values of pore volume in the two series prepared with zinc chloride are, in general terms, scarce. On the contrary, the differences are more noticeable among the series activated with phosphoric acid. Series PD exhibits a lower volume of micropores, which are also narrower (larger proportion of $\mathrm{V}_{\mathrm{CO} 2}$ ) than in series $\mathrm{PG}$, whereas $\mathrm{V}_{\mathrm{me}}$ is much larger for the later.

Figure 3 includes plots for the surface area of some activated carbons, as determined by immersion calorimetry into dichloromethane, benzene and 2,2-dimethylbutane, as a function of the minimum molecular dimension of the liquid. The carbons are the same as plotted in Figure 1 and correspond to the minimum and maximum values of surface area. This means that the micropore size distributions for the rest of carbons are similar and, for each series, they fit within the lines plotted in Figure 3.

The surface area for a given carbon determined by immersion follows the order of the molecular dimensions, $\mathrm{S}_{\mathrm{DCM}}>\mathrm{S}_{\mathrm{BZ}}>\mathrm{S}_{\mathrm{DMB}}$ and, in general, the plots are rather parallel. 
Consequently, the increase in the degree of impregnation produces micropores with dimension larger than $0.56 \mathrm{~nm}$, the micropores size distribution remaining almost constant in the $0.33-0.56 \mathrm{~nm}$ range.

On the other hand, the surface area values for series ZD (Figure 3) is always larger than in series ZG, the differences being almost constant. However, the differences are larger in series activated with phosphoric acid due to the low values for PD-0.21 and the fact that PD-0.60 and PG-0.60 exhibit similar values of surface area.

The order of micropore size distributions in Figure 3 is the same observed for the $\mathrm{N}_{2}$ adsorption isotherms, this meaning that there must be a relation between the microporosity detected by the adsorption of nitrogen and the surface area accessible to the three liquids, especially dichloromethane, with molecular dimensions $(0.33 \mathrm{~nm})$ rather near those for nitrogen $(0.36 \mathrm{~nm})$

Figure 4 shows that there is a linear relationship between the surface area measured by dichloromethane and $\mathrm{V}_{\mathrm{N} 2}$ (total volume of micropores) for series $\mathrm{ZD}, \mathrm{ZG}$ and $\mathrm{PG}$. This means that the development of the volume of micropores is paralleled by an increase in their surface area. There is also a linear relationship for series PD, but with a larger slope (larger surface area/volume ratio), thus indicating that the micropores being developed are of lower dimensions than for the other three series, contributing more to the development of surface area than to the volume. This idea was also clear in Figure 2, since series PD was the only one exhibiting an increase in the volume of narrow microporosity $\mathrm{V}_{\mathrm{CO} 2}$.

\section{Discussion}


A summary of the effect of both the different chemical used for activation $\left(\mathrm{ZnCl}_{2}\right.$ and $\left.\mathrm{H}_{3} \mathrm{PO} 4\right)$ and pressure conforming in the development of porosity is shown in Figure 5. It is clear that in the case of granular carbons (considering a given bed of particles) activation with $\mathrm{H}_{3} \mathrm{PO}_{4}$ produces a larger development of micro- and mesoporosity but a smaller development for macroporosity and voids than $\mathrm{ZnCl}_{2}$. The effect of pressure conforming is very different for the two chemicals: there is only a drastic reduction in the volume of voids and macropores after conformation for $\mathrm{ZnCl}_{2}$ activation whereas for $\mathrm{H}_{3} \mathrm{PO}_{4}$ activation the reduction affects all types of porosity, the more important the larger is the pore size. In what is follows it will be shown that the effect of pressure conforming in the development of porosity in the monoliths (discs) is mainly due to the changes that impregnation induces into the physical and chemical properties of the precursor.

Since the precursor is in a small particle size $(0.1-0.5 \mathrm{~mm})$ the chemical can easily reach the interior of the particle during impregnation and both $\mathrm{H}_{3} \mathrm{PO}_{4}$ and $\mathrm{ZnCl}_{2}$ promote the depolymerisation of the constituents of the lignocellulosic precursor into smaller units $[3,6,8]$. The effect is more pronounced when the solution is evaporated because the temperature progressively increases, as it does the concentration of the solution. The partial depolymerisation of lignin decreases the mechanical properties of the particle, thus facilitating its swelling [15], whereas the decomposition of the other components, hemicellulose and cellulose, into smaller units brings about a flow and redistribution of the cellular matter, with a high degree of mobility and migration. In fact, one can observe physical and chemical changes in the particles along impregnation and, additionally, the appearance of micelles in the solution which are converted into tar during evaporation. When the solution is completely evaporated the particles of the 
precursor have a relatively weak structure, with the entire chemical in its interior and the exterior surrounded by tars.

The changes described during impregnation (weakening of the particle structure and presence of tars) are more intense for phosphoric acid than for zinc chloride because the former is a Brönsted acid and strong dehydrating agent, thus being more effective to induce bond cleavage. Additionally, phosphoric acid has the capacity to form phosphate esters or polyphosphates with the chains of degraded biopolymers $[8,18,19]$.

When a pressure of $130 \mathrm{MPa}$ is applied to the impregnated precursor at 100 or $150^{\circ} \mathrm{C}$ the loss of water and tars from the interior of the particle continues. The changes are not very noticeable for zinc chloride because its main effect is to dehydrate, especially at temperatures above $250^{\circ} \mathrm{C}$ : the differences between the $\mathrm{ZnCl}_{2}$ series are more located in the voids and interparticle space, Table 1. However, the chemical modification produced by phosphoric acid along pressure conforming is important, thus allowing for a decrease in both porosity and interparticle space. In this way the large development of mesoporosity produced in the granular series (Figure 2) is drastically reduced by pressure. There is even a narrowing of the micropores, as deduced from the increase in $\mathrm{V}_{\mathrm{CO} 2}$ seen for series PD (Figure 2) and the small surface area accessible to 2,2dimethylbutane, Figure 3.

The precursor continues losing water and volatile matter along the heat treatment of the conformed discs, becoming richer in carbon and smaller in size, but the contraction of the particles is partially restricted by the amount of chemical in its interior. The extraction of the excess chemical controls the volume and size distribution of the micropores of the final activated carbon [4,5]. The tendency for both activating chemicals is the formation of wide micropores, as deduced from: i) the evolution in 
Figure 2 of the $\mathrm{V}_{\mathrm{N} 2}$ (total volume of micropores) in respect to $\mathrm{V}_{\mathrm{CO} 2}$ (volume of narrow micropores); ii) all micropore size distributions are parallel (Figure 3) and iii) the volume of micropores increases faster than the surface area (Figure 4).

\section{Conclusions}

Two series of monolithic activated carbons have been prepared by impregnation of olive stones with zinc chloride and phosphoric acid, conforming under pressure and heat treatment at moderate temperature. The conforming step, besides bringing together the particles it produces a decrease in the interparticle space and macroporosity of the resulting carbons. In the case of zinc chloride activation, comparison with equivalent granular activated carbon only shows a small transformation of mesopores into micropores, besides the collapse of voids and macropores. However, there is a more pronounced reduction in the volume of mesopores and the dimension of the micropores when using phosphoric acid. This modification in the porous structure of the activated carbon caused by the conforming pressure has been related to the different influence of both chemicals along the impregnation stage.

Acknowledgements: Authors acknowledge the financial support from MEC (Project MAT2004-03480-C02-02) 


\section{References}

[1] H. Marsh, F. Rodríguez-Reinoso, Activated Carbon, Elsevier, Oxford, 2006, pp.322327.

[2] F. S. Baker, C. E. Miller, A. J. Repik, E. D. Tolles, Kirk-Othmer Encyclopedia of chemical technology, vol. 4, John Wiley \& Sons, New York, 1992, p.1015.

[3] M. Molina-Sabio, F. Rodríguez-Reinoso, Colloids and Surfaces A: Physicochem. Eng. Aspects. 241 (2004) 15.

[4] F. Caturla, M. Molina-Sabio, F. Rodríguez-Reinoso, Carbon 29 (1991) 999.

[5] M. Molina-Sabio, F. Rodríguez-Reinoso, F. Caturla, M. J. Sellés, Carbon 33 (1995) 1105.

[6] M. López, M. Labady, J. Laine, Carbon 34 (1996) 825.

[7] M. Jagtoyen, F. Derbyshire, Carbon 31 (1993) 1185.

[8] M. Jagtoyen, F. Derbyshire, Carbon 36 (1998) 1085.

[9] F. Rodríguez-Reinoso, M. Molina-Sabio, C. Almansa, Spanish Patent, 2.165.784 $(2003)$.

[10] M. Molina-Sabio, C. Almansa, F. Rodríguez-Reinoso, Carbon 41 (2003) 2113.

[11] C. Almansa, M. Molina-Sabio, F. Rodríguez-Reinoso, Microporous and Mesoporous Materials 76 (2004) 185.

[12] J. Garrido, A. Linares-Solano, J. M. Martín-Martínez, M. Molina-Sabio, F. Rodríguez-Reinoso, R. Torregrosa, Langmuir 3 (1987) 76-81.

[13] F. Rodríguez-Reinoso, J. M. Martin-Martinez, C. Prado-Burguete, B. McEnaney, J. Phys. Chem. 91 (1987) 515.

[14] ASTM Standard Test Method for Apparent Density of Activated Carbon 1989, Designation: D 2854-89. 
[15] R. Denoyel, J. Fernandez-Colinas, Y. Grillet, J. Rouquerol, Langmuir 9 (1993) 515.

[16] F. Kraehenbuehl, H. F. Stoeckli, Carbon 24 (1986) 483.

[17] F. Rouquerol, J. Rouquerol, K. S. W. Sing, Adsorption by powders and porous solids, Academic Press, London, 1999.

[18] H. Benaddi, D. Legras, J. N. Rouzaud, F. Beguin, Carbon 36 (1998) 306.

[19] A. M. Puziy, O. I. Poddubnaya, A. Martínez-Alonso, F. Suárez-García, J. M. D. Tascón, Carbon 40 (2002) 1493. 


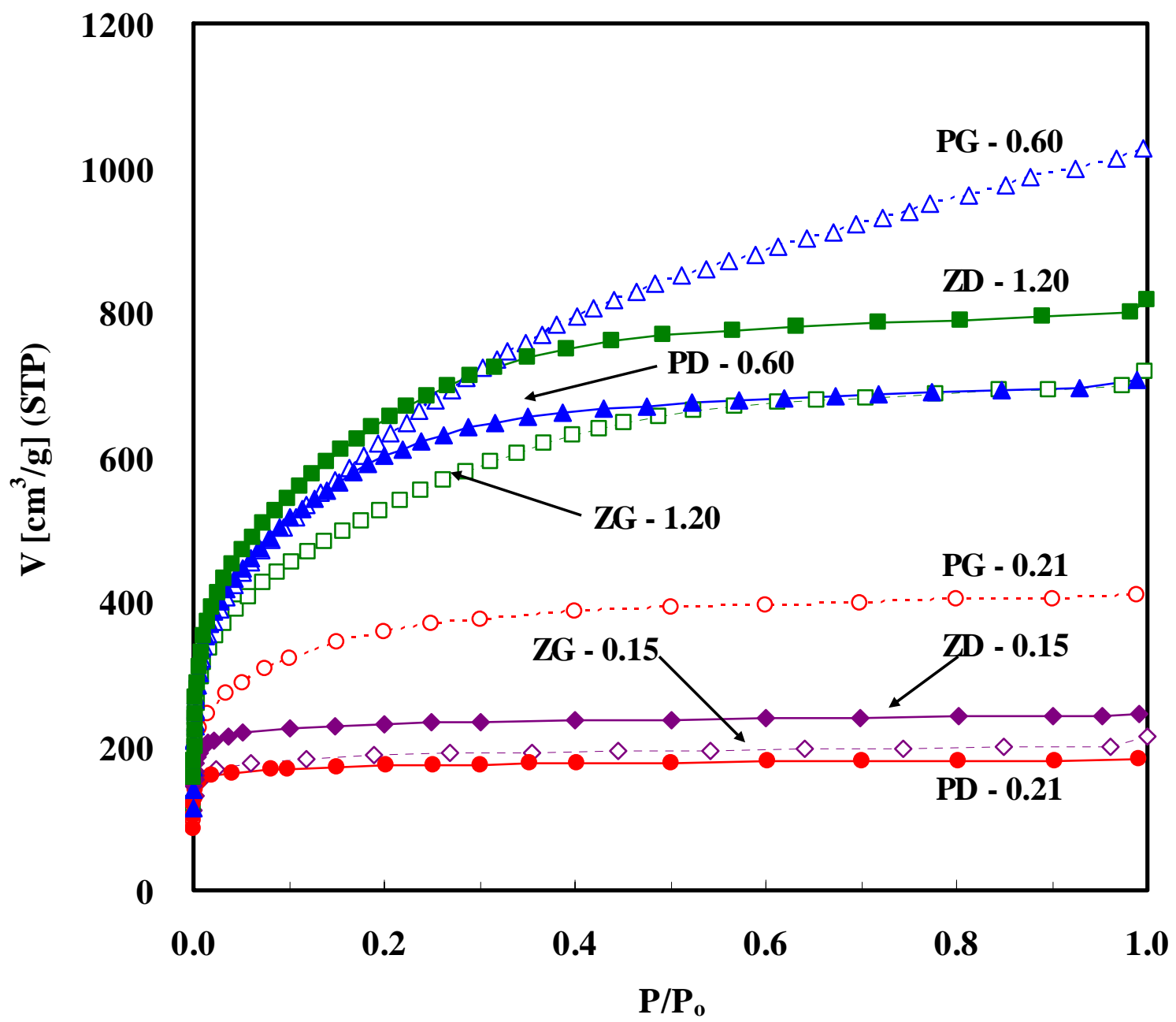

Figure 1. Adsorption isotherms of $\mathrm{N}_{2}$ at $-196^{\circ} \mathrm{C}$ for some carbons activated with zinc chloride and phosphoric acid. 


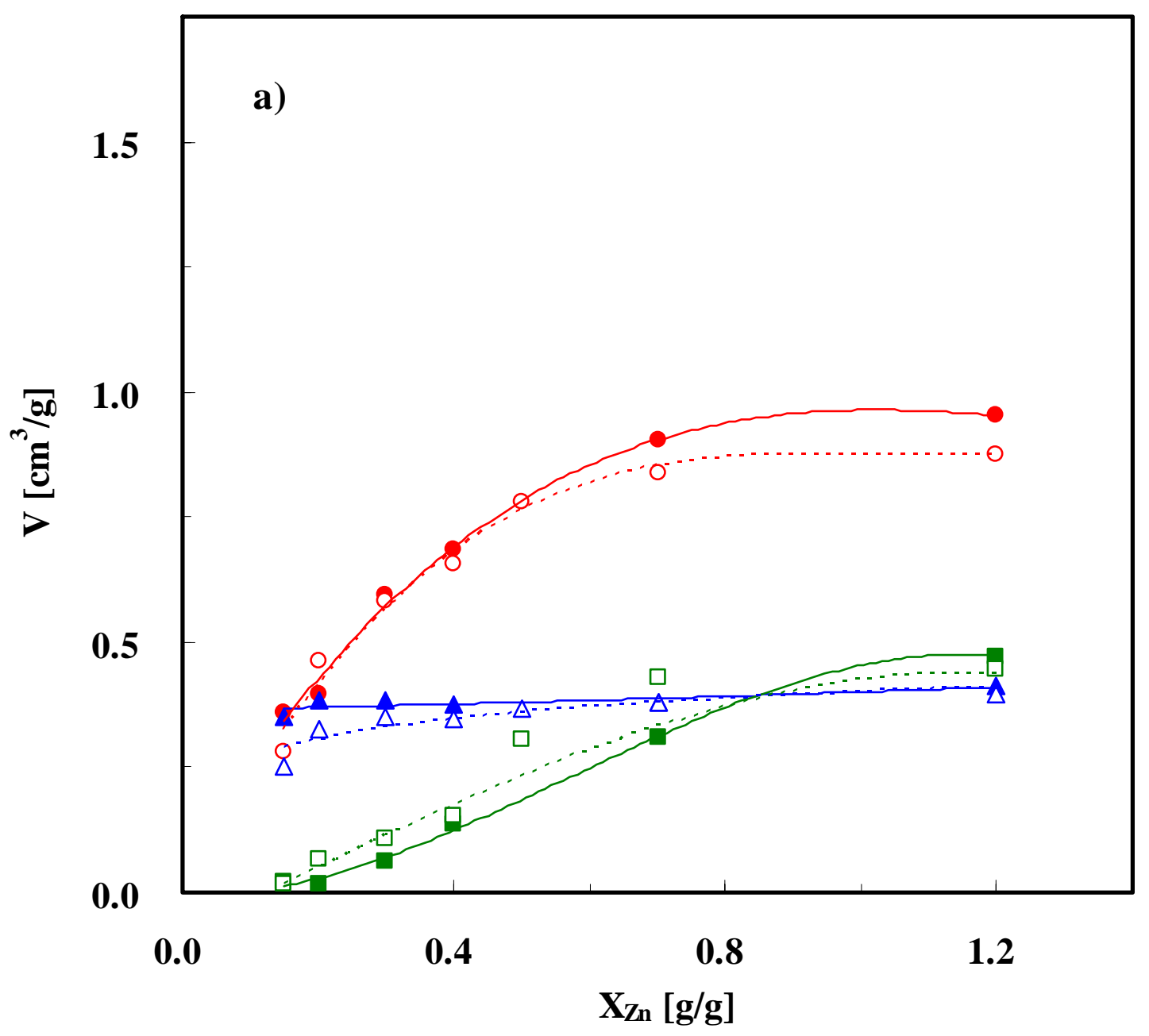

Figure 2 a). Evolution of different sets of pore volume along activation with a) zinc chloride. Symbols: $\mathrm{V}_{\mathrm{N} 2}(\bullet) ; \mathrm{V}_{\mathrm{CO} 2}(\boldsymbol{\Delta}) ; \mathrm{V}_{\mathrm{me}},(\mathbf{\bullet})$; discs series, filled symbols; granular series, open symbols. 


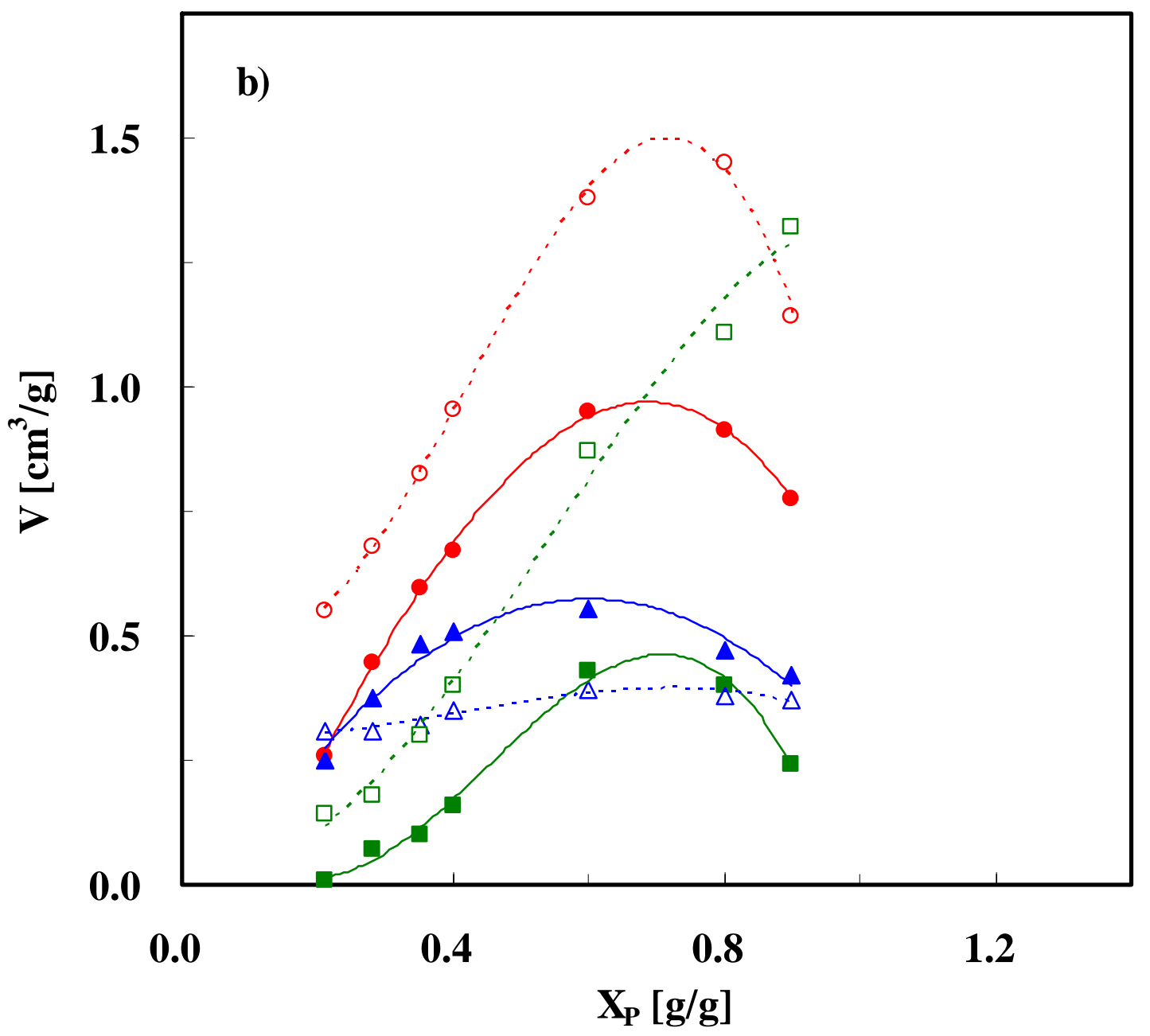

Figure $2 \mathrm{~b}$ ). Evolution of different sets of pore volume along activation with b) phosphoric acid. Symbols: $\mathrm{V}_{\mathrm{N} 2}(\bullet) ; \mathrm{V}_{\mathrm{CO} 2}(\boldsymbol{\Delta}) ; \mathrm{V}_{\mathrm{me}},(\boldsymbol{\bullet})$; discs series, filled symbols; granular series, open symbols. 


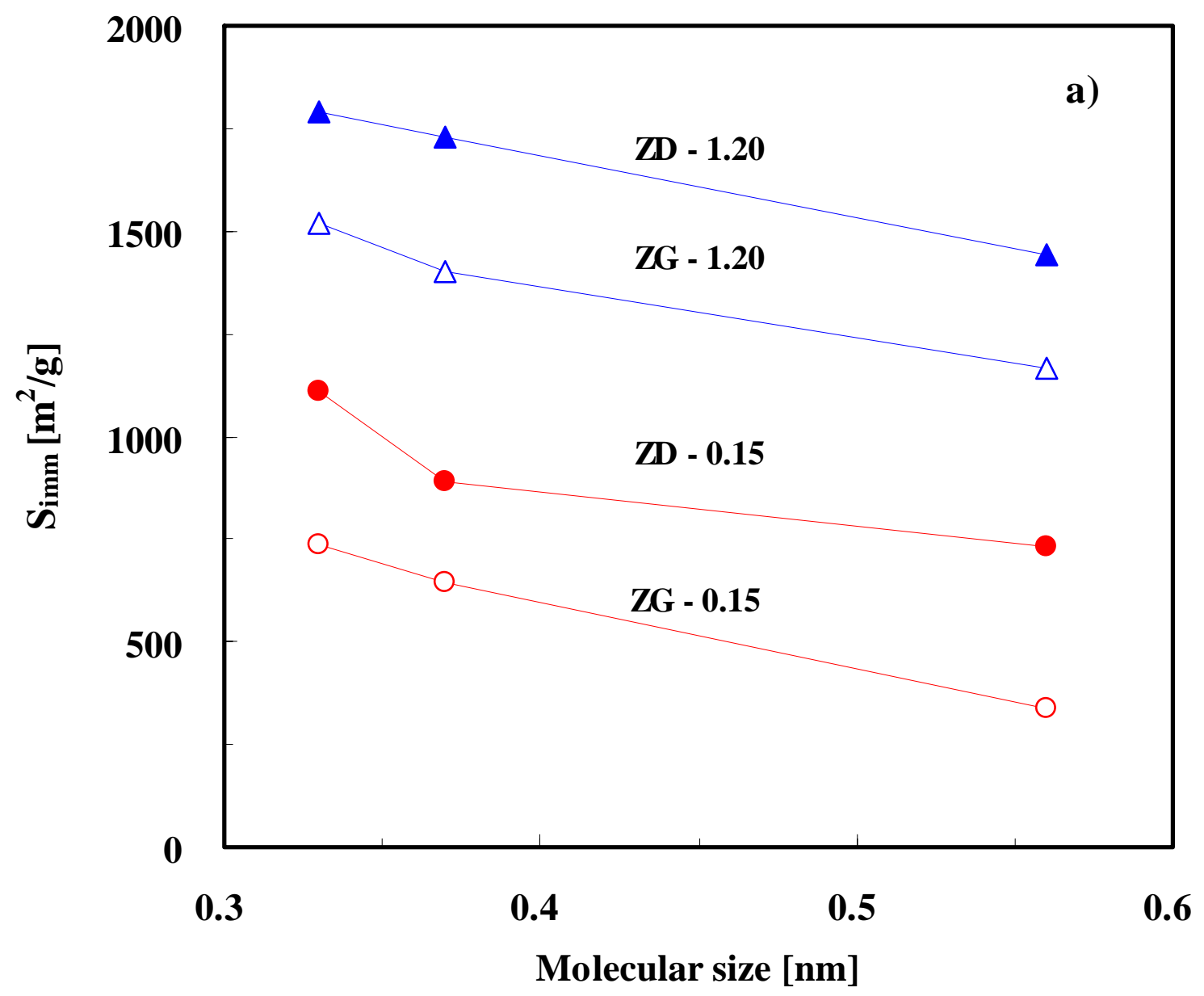

Figure 3 a). Micropore size distribution of some carbons activated with a) zinc chloride. Surface area values has been deduced from immersion enthalpy in dichloromethane, benzene and 2,2-dimethylbutane. 


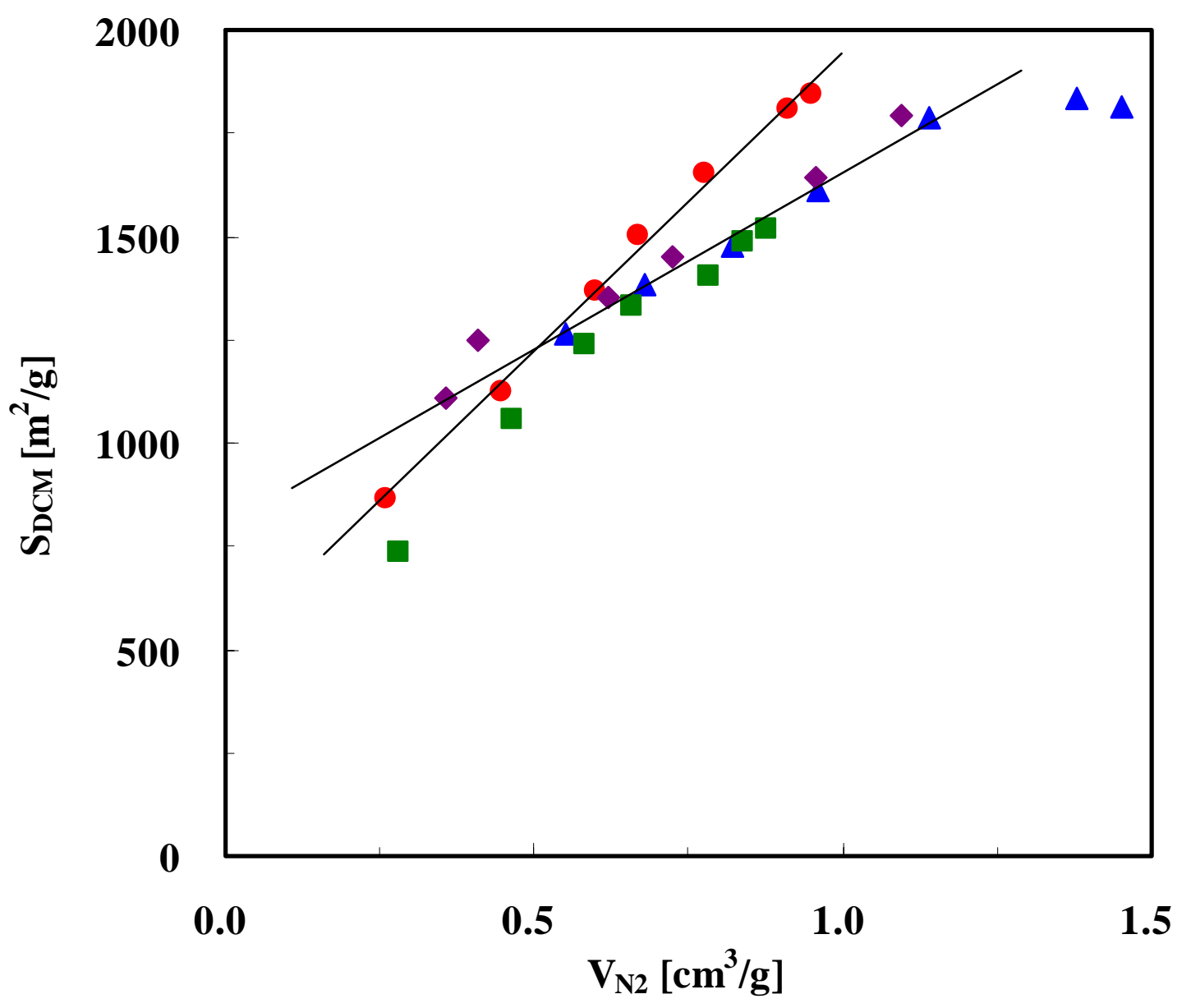

Figure 4. Relationship between the micropore volume from $\mathrm{N}_{2}$ adsorption and the surface area from immersion enthalpy in dichloromethane. Series ZD; $\square$ Series ZG; • Series PD; $\Delta$ Series PG. 

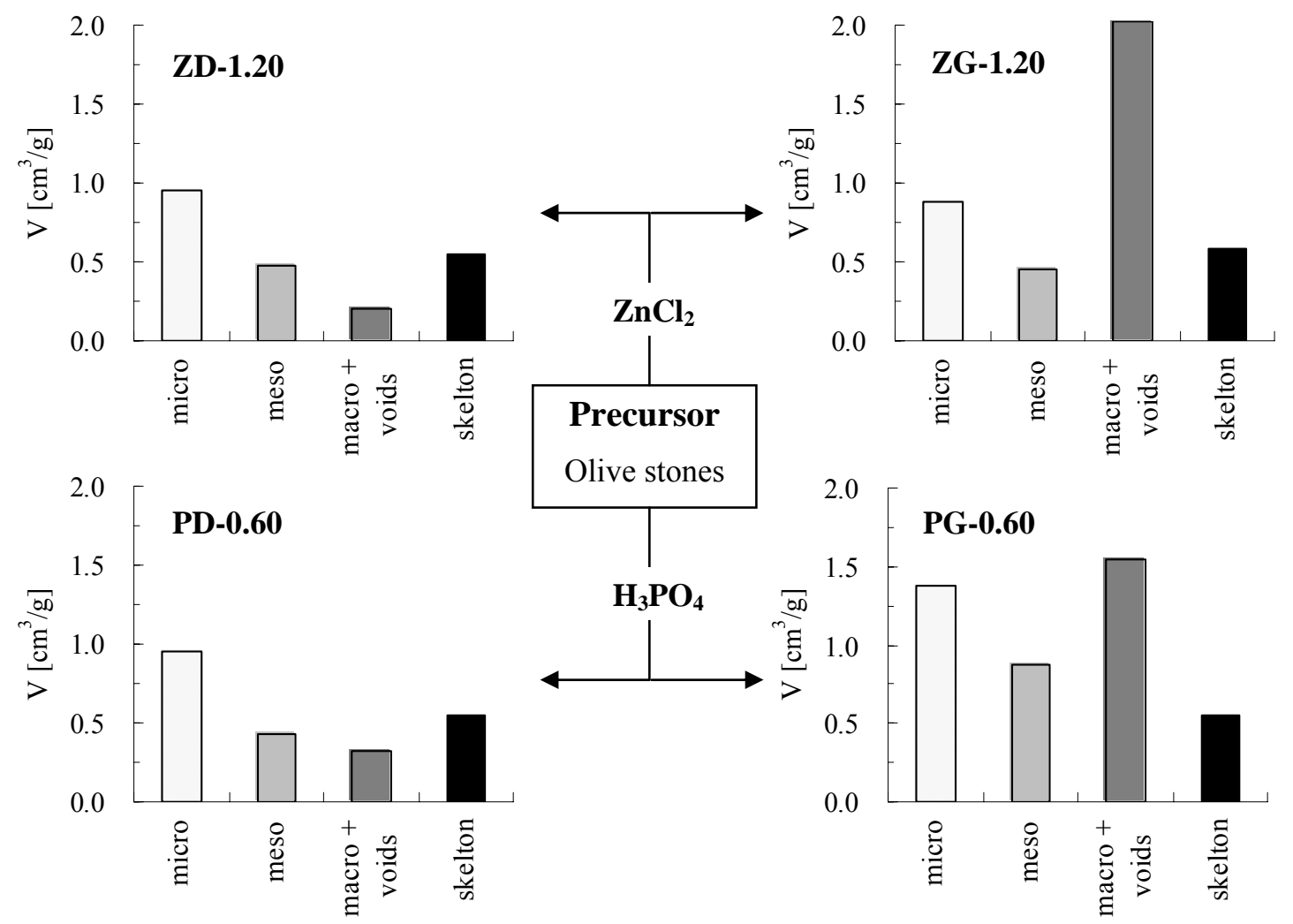

Figure 5. Effect of the two chemicals and pressure conforming in the volumes of micropores, mesopores, voids and macropores, and carbon skeleton. 
Table 1. Density $\left(\mathrm{g} / \mathrm{cm}^{3}\right)$ and volume $\left(\mathrm{cm}^{3} / \mathrm{g}\right)$ of some activated carbons.

\begin{tabular}{rccccc}
\hline Carbon & He density & Bulk density & Voids and & $\mathrm{V}_{0.99}$ & Voids and \\
& & & porosity & & macropores \\
\hline ZD-0.15 & 1.63 & 0.90 & 0.50 & 0.37 & 0.13 \\
ZD-1.20 & 1.80 & 0.50 & 1.44 & 1.24 & 0.20 \\
ZG-1.20 & 1.59 & 0.60 & 1.05 & 0.31 & 0.74 \\
PD-0.21 & 1.72 & 0.27 & 3.14 & 1.11 & 2.03 \\
PD-0.60 & 1.83 & 0.91 & 0.45 & 0.28 & 0.17 \\
PG-0.21 & 1.67 & 0.51 & 1.41 & 1.09 & 0.32 \\
PG-0.60 & 1.83 & 0.27 & 1.22 & 0.63 & 0.58 \\
\hline
\end{tabular}

